\title{
An exploratory study of the role played by sustained attention along a rural Irish route using a video-playback system
}

\author{
Noel Daly ${ }^{\mathrm{a}}$, Michael Brogan ${ }^{\mathrm{b}}$, David Kaneswaran ${ }^{\mathrm{c}}$, Catherine Deegan ${ }^{\mathrm{b}}$, Charles Markham ${ }^{\mathrm{c}}$, \\ Sean Commins ${ }^{\text {a,* }}$ \\ a Department of Psychology, NUI Maynooth, Co. Kildare, Ireland \\ ${ }^{\mathrm{b}}$ Department of Engineering, IT Blanchardstown, Dublin, Ireland \\ ${ }^{\mathrm{c}}$ Department of Computer Science, NUI Maynooth, Co. Kildare, Ireland
}

\section{A R T I C L E I N F O}

\section{Article history:}

Received 9 December 2013

Received in revised form 21 March 2014

Accepted 27 June 2014

\section{Keywords:}

Driver behaviour

Sustained attention

Rural roads

Gender

\begin{abstract}
A B S T R A C T
Inattention and distractibility are major causes of driver accidents. Using a video playback system with a video sequence taken from a rural Irish road, we compared the speed of those considered as having either high or low levels of sustained attention along the route, as well as, at targeted sections of the road. In addition, we manipulated the video sequence by adding a speed limit sign (augmented sequence) or by removal of the middle white line (redacted sequence) to determine how each group would react. Results revealed that those with high sustained attention showed generally lower speeds compared to those with low sustained attention with a significant difference between the groups at bends. Further, although no difference in reaction was found for any particular manipulated sequence, the high sustained attention group was found to be significantly slower at these locations. In addition, some gender differences were observed, females showed significantly lower speeds on straight stretches of road and at a school compared to male drivers. These results would suggest that both attentional capacity and gender should be considered as separate entities in future driving research and theoretical models.
\end{abstract}

(c) 2014 Elsevier Ltd. All rights reserved.

\section{Introduction}

Road deaths in Ireland have decreased dramatically over the last number of years, from a fatality rate of 232 per million registered vehicles in 2001 to 77 per million registered vehicles in 2011. Despite this, 186 people were killed and 7235 people were injured in 2011 (Road Safety Authority of Ireland (RSA), 2011). The majority (65\%) of the car drivers killed were male and 30\% of deaths were aged under 24. Collision reports from An Garda Síochána (Irish Police Force) have indicated that driver error accounted for $84 \%$ of all contributory factors identified in fatal collisions and injuries in 2011 , with the most frequently cited contributory action was 'went to the wrong side of the road' (33\%) followed by 'drove through stop/yield sign' (15.9\%) and 'exceeded safe speed limit' (6.4\%; Road Safety Authority of Ireland (RSA), 2011). While not specifically mentioned, inattention and distractibility may be important factors in causing driver error.

Inattention is also one of the major factors that contributes to road traffic accidents internationally. According to the United States Department of Transportation 2010 statistics, nearly 6000 people died in crashes involving a distracted or inattentive driver (Pradhan et al., 2011). Data from Australia (McEvoy, Stevenson, \& Woodward, 2007) suggest that driver

\footnotetext{
* Corresponding author.

E-mail address: Sean.Commins@nuim.ie (S. Commins).
} 
distraction may account for between $14 \%$ and $33 \%$ of all serious crashes, with lack of concentration, passengers and outside factors all being cited as major causes of driver distraction. This study compares favourably with research from Norway, which also cites passengers, in-vehicle factors (e.g. mobile use) and outside factors (e.g. searching for signs or street names) as the main causes of driver distractibility and inattention (Sagberg, 2001). In a more recent study, where 100 cars were fitted with video-recording equipment and monitored for a year to determine causes of accidents, it was found that $22 \%$ of crashes and near-crashes were due to secondary task distraction (Klauer, Dingus, Neale, Sudweeks, \& Ramsey, 2006), including in-vehicle passengers (9\%), dialling a hand-held device (3.6\%), talking on a hand-held device (3.6\%), and reading (2.9\%; Dingus et al., 2006).

Inattention is also thought to be the leading cause of accidents among various at risk groups. For example, Lestina and Miller (1994) analysed 1396 police reports detailing traffic accidents in California and identified inattention as being a major cause of accidents among young novice drivers. A failure to adequately assess the road ( $39 \%$ of accidents) and a failure to observe the rules of the road (18\%) were the most frequently cited causes of accidents among drivers under the age of 20. Similarly, Lee, Olsen, and Simons-Morton (2006) found that novice drivers spent significantly more time looking away from the roadway while performing in-vehicle tasks compared to experienced drivers. Gender differences have also been reported in accident statistics, with the fatality rate for males in the United States being three times higher than females (Kelley-Baker \& Romano, 2010). Male drivers are thought to engage more in riskier behaviour compared to females (Harré, Brandt, \& Dawe, 2000). More specifically, Al-Balbissi (2003) identified that males were worse than females at violating stop signs, using incorrect lanes, violating yield signs, disregarding obligatory signs, and wrong overtaking. The author explains these behaviours in terms of reduced attention and less cautious driving behaviour amongst male drivers.

Attention is defined as the ability to allocate processing resources to particular stimuli (Robertson I. H., in press). Attention, however, is not a unitary process with Posner and Petersen (1990) advocating 3 separate attentional processes: selective attention, attention switching, and sustained attention. While driving requires the ability to pay attention to certain features on the road while ignoring others (selective attention) and the ability to switch your attention should an unforeseen event arise (switching attention), it is the ability to maintain the focus of cognitive activity on the driving task at hand (sustained attention) that is thought to be a critically important (Staub, Doignon-Camus, Després, \& Bonnefond, 2013). For example, many drivers show fatigue and loss of sustained attention during long monotonous drives, particularly at night, which can lead to very serious accidents (Campagne, Pebayle, \& Muzet, 2004). Such failures in sustained attention are currently explained in terms of two theoretical frameworks: the resource depletion model and the mindlessness model. The resource depletion model (Davies \& Parasuraman, 1982) advocates that vigilance loss is due to a decline in attentional resources with time, while the mindlessness model (Manly, Robertson, Galloway, \& Hawkins, 1999) suggests that the repetitive nature of the task leads participants to perform the task in a mindless fashion and are therefore easily distracted.

Interestingly, recent research in the driving domain has attempted to account for differences in driver behaviour in terms of attentional differences, particularly attentional capacity (Pradhan et al., 2011). This idea fits with various driving models, as well as the various sustained attention models. For example, the task-capability interference (TCI) model (Fuller, 2000, 2005), emphasise that when the demands of the driving task exceeds the capabilities of the driver, there is a loss of control which, in turn, may lead to collisions and accidents. Although not explicitly stated in this model, attention may play a role in the range of human factors that can influence driver capability. Therefore you might predict that someone with a high attentional capacity, particularly sustained attention, would have greater 'spare capacity' (see Rubio, Diaz, Martin, \& Puente 2004) and would be in a better position to deal with unexpected events that may arise while driving. On the other side of the TCI model, driving task demand can also affect levels of arousal and subsequent driver capability (Fuller, 2005). Indeed, many researchers have found a high correlation between feelings of risk, task difficulty and effort (Fuller, McHugh, \& Pender, 2008; Lewis-Evans, de Waard, Jolij, \& Brookhuis, 2012; Lewis-Evans \& Rothengatter, 2009). Accordingly, as the demands of the environment increase, more effort (mental and/or physical) is required to match such demands (Lewis-Evans \& Rothengatter, 2009). Therefore, the more effort that is employed by an individual the more their capacity decreases-as a result the driver's ability to match environmental demands also decreases (Fuller, 2000, 2005; Lewis-Evans \& Rothengatter, 2009). Again, we would suggest that an individual with higher attentional capacity would be in a better position to deal with increased demands of the task.

Attentional capacity is not static and is liable to change throughout the lifespan. As brain regions devoted to executive functioning, including attention, develop mainly during late adolescence and early 20s (Blakemore \& Choudhury, 2006), it is possible that developmental factors may have an impact on attentional capacity and the greater distractibility observed in younger drivers. These developmental factors are often very difficult to measure. To complicate matters, late adolescence and early 20s is also the age when people first learn to drive, therefore more experienced drivers, due to practice, may also have a greater attentional capacity and thus are able to devote more resources to 'other' aspects of driving, e.g. scanning, watching for hazards etc (Pradhan et al., 2011). Although attentional capacity itself is difficult to measure, tasks (e.g. Continuous Performance Task, Rosvold, Mirsky, Sarason, Bransome, \& Beck, 1956; Digit Detection task, Nuechterlein, Parasuraman, \& Jiang, 1983; Sustained Attention to Response Task, Robertson, Manly, Andrade, Baddeley, \& Yiend, 1997) that measure a person's ability to maintain vigilance, avoid distraction and prevent lapses in attention may serve as a useful proxy for measuring capacity. Using these tasks it may be possible to examine the idea of whether those with higher attentional capacity react better to road situations that require particular attention (e.g. multiple bends, hazards) compared to those with less attentional capacity. In addition, do those with a higher attentional capacity have more 'spare capacity' allowing them to scan and notice their environment more than those with a lower attentional capacity? Therefore, using 
a video playback of an Irish rural road we hypothesise that people who have been classified as having a high attention capacity or a low distractibility rate will, irrespective of the age or driving experience, react more appropriately upon approaches to specific 'high demand locations' (e.g. reducing speed at bends, hazards and approaches to schools). In addition, we propose to change the video sequence by adding or subtracting features in the environment which may serve to increase task demand. Therefore, if those classified as having high attention do have 'spare capacity' to scan their environment we would hypothesise that these participants will show greater reactivity to the changed environment compared to those with lower attentional capacity.

\section{Method}

\subsection{Participants}

Forty-one participants (20 males and 21 females), aged between 19 and 33 with a mean age of 23 , took part in the study. Participants were recruited via an ad hoc sampling method of convenience from the student population of the National University of Ireland Maynooth (NUI Maynooth). All participants were in good health with no dizziness or motion sickness conditions. No participant suffered from Attention deficit hyperactivity disorder (ADHD) or had any other attentional issues. All had normal or corrected-to-normal vision. Over 90\% of participants had greater than 6 months of driving experience. The remaining participants had a full Irish driving licence. The average number of months spent driving was $35.6 \pm 4.1$. In addition, the average score on a self-rating scale of driving ability was $6.75 \pm 0.2$ (on a scale of $1-10,1$ being poor and 10 being excellent). Therefore our participants would be generally be classified as being experienced drivers (see Mueller \& Trick, 2012; Pradhan et al., 2005).

\subsection{Driving measures}

\subsubsection{Demographic questionnaire}

An 8-item questionnaire was designed in order to gain general information about the participants and their driving experience. The questionnaire was used to determine the participants. age, driving licence type, the number of years of driving experience accumulated under their current licence, where the participants do most of their driving (urban, rural, or both), and whether they were familiar with the simulated route. Items were also included to determine whether participants had any medical conditions that prevent them from driving, whether they had ever experienced car sickness or any form of motion sickness, and whether they had ever been involved in a traffic accident as a driver.

\subsubsection{Video playback system}

In order to create a realistic testing environment for the participants a static, fixed-base driving system was built. This consisted of a wooden mock-up cabin with primary controls; a Logitech G27 steering wheel with force feedback, primary pedals and gear stick. The driver seat was a standard driving seat adapted from an end-of-life vehicle. The video sequence (see below) was displayed on a triple screen (three 1024 by 768 monitors interfaced to the PC as a single 3072 by 768 ) run through a standard Windows 7-based PC, containing an Intel Quad-Core Xeon processor and a Nvidia graphics card. The driver was positioned facing the centre screen, and the other two screens oriented at approximately $\pm 30^{\circ}$.

The video sequence was integrated into the driving simulator by way of the OpenCV image processing library (Bradski \& Kaehler, 2008). This allowed for the video sequence to have its playback speed linked directly to the pressure applied to the accelerator pedal. Speed was the primary dependent measure used in this study. The playback speed of the video was adjusted based on value of accelerator depression- a fully pressed accelerator pedal was interpreted as full speed playback, returned to the user via an on-screen display as $130 \mathrm{~km} / \mathrm{h}$. Similarly, a fully released accelerator pedal was interpreted as a paused playback speed, again, returned to the user via an on-screen display as $0 \mathrm{~km} / \mathrm{h}$ (see Fig. 1a).

The video sequence was acquired by a low-profile Mobile Mapping System (MMS). This MMS acquired full-colour stereo images alongside Global Positioning System (GPS) positional data and roll, pitch, yaw orientation data at a rate of $10 \mathrm{~Hz}$. The system consisted of a stereo camera system mounted on a vehicle, and a navigational system that acquired the positional and orientation data mounted in the boot of the vehicle. The field of view of the camera was 66 degrees with a $3.8 \mathrm{~mm}$ lens focal length. The system was driven at standard road speeds along the selected route: the R156 from Dunboyne to Summerhill, in Co. Meath, Ireland. The route is rural and is classified by the National Roads Authority of Ireland (NRA) (2009) as 'regional,. The chosen route is $13 \mathrm{~km}$ in length with a maximum speed limit of $80 \mathrm{~km} / \mathrm{h}$, and takes approximately 17 min to complete. The route was chosen as it offered a rapidly-changing geometry with a wide range of road signage and other delineation features.

Four locations of interest were selected and analysed in detail: bend 1, bend 2, stretch of straight road, and a school. The first bend covered a distance of approximately $600 \mathrm{~m}$ of road. Upon approach a number of signs were visible to the driver. These included a warning sign indicating 'a series of dangerous bends ahead', a $50 \mathrm{~km} / \mathrm{h}$ speed limit sign and a cheveron board at the bend itself. In addition, a single white continuous line in the middle of the road which indicates no overtaking is permitted was also visible. The second bend covered a stretch of approximately $800 \mathrm{~m}$ and had similar displays including: a warning sign indicating 'a series of dangerous corners ahead', a sharp corner sign with a label 'reduce speed now', 
(a)

(b)
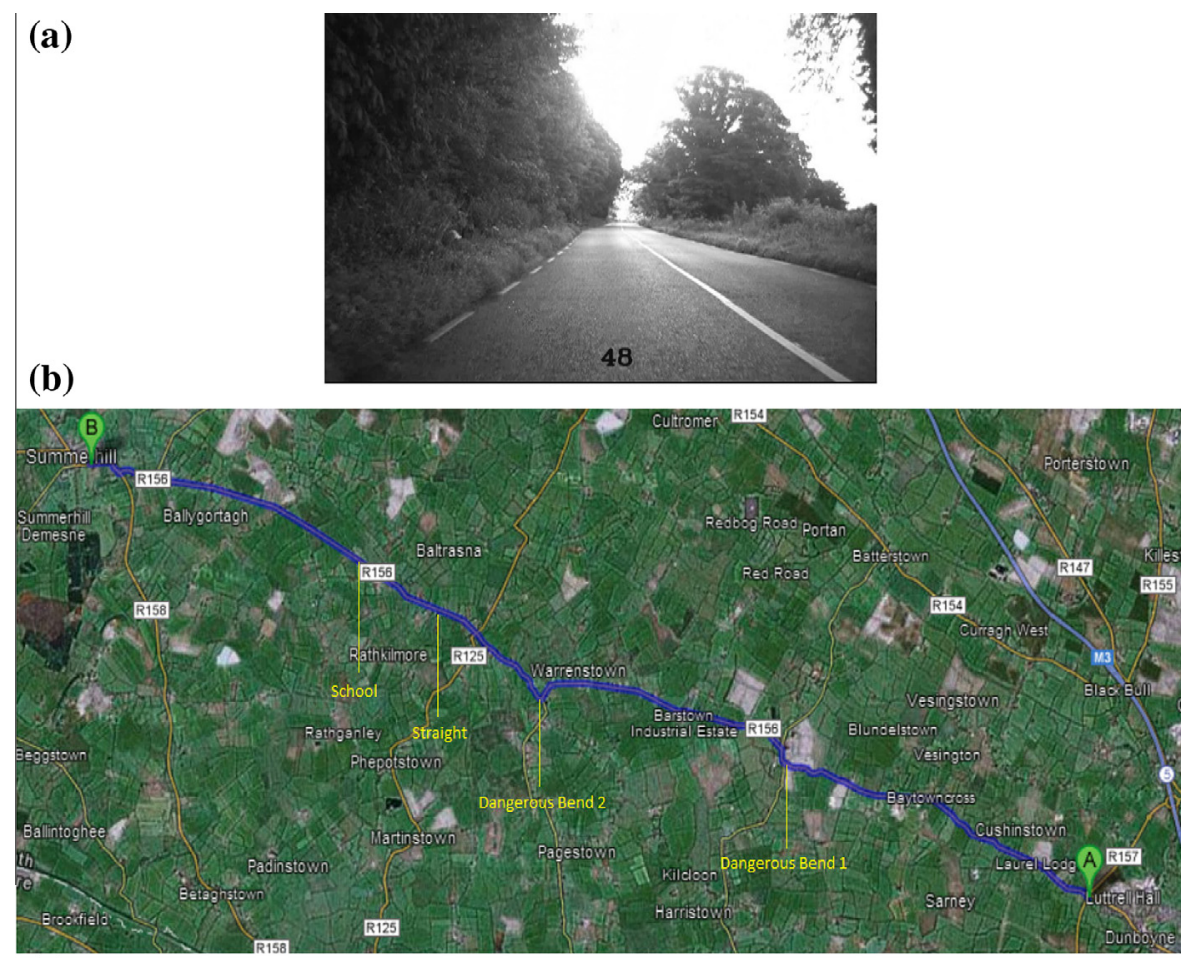

(c)

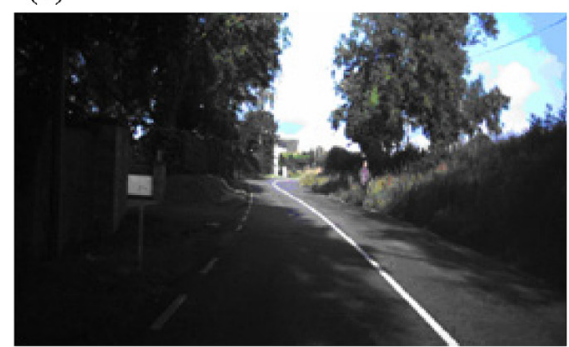

(a)

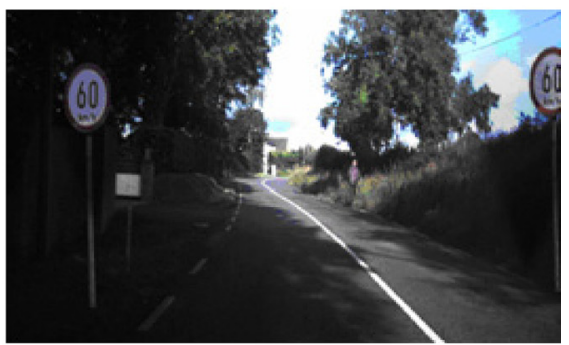

(b)

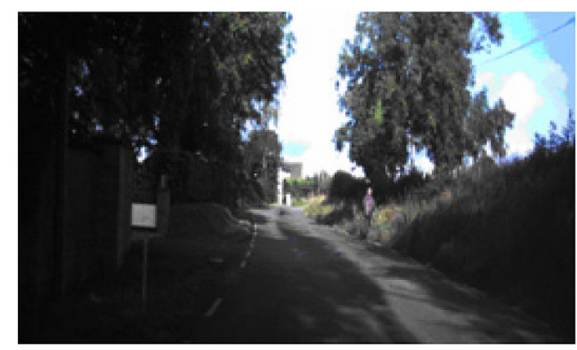

(c)

Fig. 1. (a) Representative snapshot of the video sequence of the route along with speed feedback to the driver. (b) The R156 road from Dunboyne (A) to Summerhill (B), Co. Meath, Ireland taken from Google Earth, with the locations of the four points of interest (bend 1, bend 2, stretch of straight road, and the school) highlighted. (c) Representative snapshots of (a) unaltered video frame, (b) augmented video frame (60 km/h speed limit signs), and (c) redacted video frame (erased central road line).

a cheveron board at the bend and a single white continuous line in the middle of the road. The straight stretch of road was approximately $2 \mathrm{~km}$ in length and had a $80 \mathrm{~km} / \mathrm{h}$ speed limit sign. In addition, the stretch had a single white broken line in the middle of the road which indicates that overtaking is permitted if safe to do so. Upon approach to the school a number of signs were again visible. These included a sign which indicated a 'school ahead', a caution 'children crossing' sign, a $50 \mathrm{~km} / \mathrm{h}$ speed limit sign and a single white continuous line in the middle of the road. The R156 road, along with the locations of the four main points of interest, is illustrated in Fig. $1 \mathrm{~b}$.

We also wanted to examine whether manipulations of road features in the video sequence would affect behaviour. Three additional stretches of road of similar geometry (straight) and length (approximately $3 \mathrm{~km}$ ) were chosen as sites for 
manipulation. Note that these sites were separate to the 4 locations of interest described above. Three different stretches were chosen in order to counter any bias in the road geometry that might serve to change the driver's behaviour, rather than the experimental manipulation itself. Each of the three locations was either (1) left unaltered, (2) augmented or (3) redacted. All participants, when driving, encountered each of these locations once only. An unaltered road segment consisted of video frames as originally acquired by the data acquisition system. The video playback was true to the condition of the road at the time of image acquisition. An augmented road segment consisted of a segment where the speed limit was changed through the insertion of $60 \mathrm{~km} / \mathrm{h}$ speed limit signs, either at the start of, or directly preceding the start of, that segment. A redacted road segment consisted of video frames where the central road line was redacted (erased) to give the appearance of no central line for the entire duration of that segment (see Fig. 1c).

\subsection{The SART and other measures}

The Sustained Attention to Response Task (SART; Robertson et al., 1997) is a test designed to mimic real life situations whereby an ongoing behaviour must be inhibited upon the occurrence of a rare event (Staub et al., 2013). The test has been used successfully to demonstrate poor attentional performance in many populations including stroke survivors (Levine et al. 2011), elderly (O'Halloran et al., 2014) and children with ADHD (Christakou et al., 2013). It is a Go/No-Go measure of sustained attention which involves participants making key presses in response to 225 stimuli that are presented in random order on a computer screen. For each of the 225 trials, a single digit (1-9) was presented in the centre of the screen. Each digit was presented for $250 \mathrm{~ms}$, following this a circle with a diagonal cross was presented for 900 ms. The participant's task was to withhold key presses to one (the digit "3") in every nine presentations of the 225 target stimuli. Lower accuracy scores and/or a failure to withhold when 3 is present were interpreted as lapses in attention, with such errors understood to signify impairment of sustained attention (see Robertson et al., 1997 for details).

Two control tests, the National adult Reading Test (NART, Nelson \& McKenna, 1975) and the Trail Making Test (TMT, Reiten, 1958) were also employed to ensure that all participants were comparable in terms of intelligence and general executive functioning. The NART is considered a measure of premorbid intelligence in which participants are required to read aloud 50 phonetically irregular words, words whose pronunciation cannot be determined from their spelling. The words were presented on a single sheet. Words were presented in order of increasing difficulty. Examples of words on the test include 'gaoled', 'beatify', and 'demense'. As the application of standard phoneme-grapheme rules will not produce the correct pronunciation, the NART is designed to assess whether participants have previously learned the pronunciation of the words. The NART has been standardised against the Wechsler Adult Intelligence Scale - Revised (WAIS-R) in order to produce estimates of Full Scale IQ (FSIQ), Performance IQ (PIQ) and Verbal IQ(VIQ) from the number of errors made by participants on the NART.

The TMT is a measure of executive functioning that requires participants to draw lines between 25 circles presented on a sheet of paper. The TMT is thought to measure various cognitive processes including attention, visual search and scanning, sequencing, cognitive flexibility and processing speed (Ashendorf et al., 2008; Sánchez-Cubillo et al., 2009). The test comprises two parts; A and B. In part A (TMT-A), the circles contain the numbers 1 to 25 , with the participant's task being to connect the numbers in ascending order (i.e. 1-2-3-4, etc.). In part B (TMT-B), the circles contain the numbers 1-13 and the letters A-L, with the participant's task again being to connect the circles in ascending order, but this time with the additional task of alternating between numbers and letters (i.e. 1-A-2-B, etc.). For both parts, the circles are randomly distributed across the sheet. Participants were instructed to connect the circles as quickly as possible, without lifting the pen or pencil from the sheet of paper. The scores for TMT-A and TMT-B were recorded as the amount of time (in seconds) the participants required to complete the tasks.

\subsection{Procedure}

Participants were required to give their informed consent for participation in the study. Participants were informed that there was a potential risk of motion sickness associated with use of the driving simulator, and that they could cease participation at any time during the study should they feel unwell. Once participants had given their informed consent, they were asked to complete the driving behaviours questionnaire. Since none of the participants stated that they had previously experienced car sickness or motion sickness, all participants were allowed to participate in the remainder of the study. Participants then completed the SART. Participants were instructed to make their key press responses as quickly as possible once the digits appeared, with the exception of the No-Go digit ' 3 ', for which participants were instructed to withhold from pressing the key. Next, the participants completed the TMT. The speeds at which the participants completed TMT-A and TMT-B were recorded using a stopwatch. Participants were then asked to read aloud the 50 words on the NART. The accuracy of the participants' pronunciation of each word was recorded as the participants read the words aloud.

The participants were then asked to sit into the driving system. Participants were asked to drive as if they were driving on a real road, that is, to take the same action that they would if they were driving in reality. The only other instruction that the participants were given was that the default speed limit on the road was $80 \mathrm{~km} / \mathrm{h}$, which was determined by the speed limit specified for regional roads by the RSA. As the participants performed the driving simulation, the frame numbers and the speed associated with each frame number were recorded. This generated data consisting of 14,000 speed-frame points. For analysis every 250 points were averaged (corresponding to approximately $15 \mathrm{~s}$ ) giving 56 data points for the entire route. 
Table 1

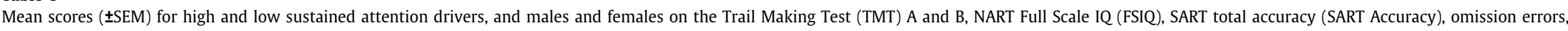
commission errors, response time for commission errors (C.E.) and response time. Bold represents that the values have reached significance at the 0.05 level

\begin{tabular}{|c|c|c|c|c|c|c|c|c|c|c|}
\hline & Driving experience (months) & Age & TMT (A) & TMT (B) & NART FSIQ & SART accuracy & Omission errors & Commission errors & Response time C.E. (ms) & Response time (ms) \\
\hline High Attention & $\begin{array}{l}41.0 \\
( \pm 5.8)\end{array}$ & $\begin{array}{l}24.52 \\
( \pm 1.06)\end{array}$ & $\begin{array}{l}20.38 \\
( \pm 1.0)\end{array}$ & $\begin{array}{l}40.8 \\
( \pm 2.2)\end{array}$ & $\begin{array}{l}102.8 \\
( \pm 1.7)\end{array}$ & $\begin{array}{l}208.8 \\
( \pm 0.97)\end{array}$ & $\begin{array}{l}2.76 \\
( \pm 0.6)\end{array}$ & $\begin{array}{l}13.38 \\
( \pm 0.7)\end{array}$ & $\begin{array}{l}210.9 \\
( \pm 10.5)\end{array}$ & $\begin{array}{l}265 \\
( \pm 8.5)\end{array}$ \\
\hline Low Attention & $\begin{array}{l}30.1 \\
( \pm 5.7) \\
t=1.322 \\
\mathrm{df}=39 \\
\mathrm{p}=0.194\end{array}$ & $\begin{array}{l}22.35 \\
( \pm 0.6) \\
t=1.742 \\
\mathrm{df}=39 \\
\mathrm{p}=0.089\end{array}$ & $\begin{array}{l}19.55 \\
( \pm 0.93) \\
t=0.593 \\
\mathrm{df}=39 \\
\mathrm{p}=0.556\end{array}$ & $\begin{array}{l}39.8 \\
( \pm 2.3) \\
t=0.313 \\
\mathrm{df}=39 \\
\mathrm{p}=0.756\end{array}$ & $\begin{array}{l}103.7 \\
( \pm 1.7) \\
t=-0.396 \\
\mathrm{df}=39 \\
\mathrm{p}=0.694\end{array}$ & $\begin{array}{l}192.1 \\
( \pm 2.07) \\
t=7.437 \\
\mathrm{df}=39 \\
\mathrm{p}=0.001\end{array}$ & $\begin{array}{l}12.3 \\
( \pm 1.8) \\
t=-4.864 \\
\mathrm{df}=39 \\
\mathbf{p}=\mathbf{0 . 0 0 1}\end{array}$ & $\begin{array}{l}20.6 \\
( \pm 0.6) \\
t=-7.163 \\
\mathrm{df}=39 \\
\mathbf{p}=\mathbf{0 . 0 0 1}\end{array}$ & $\begin{array}{l}148.8 \\
( \pm 10.9) \\
t=4.077 \\
\mathrm{df}=39 \\
\mathbf{p}=\mathbf{0 . 0 0 1}\end{array}$ & $\begin{array}{l}202.5 \\
( \pm 11.1) \\
t=4.491 \\
\mathrm{df}=39 \\
\mathbf{p}=\mathbf{0 . 0 0 1}\end{array}$ \\
\hline Male & $\begin{array}{l}33 \\
( \pm 6.4)\end{array}$ & $\begin{array}{l}23.8 \\
( \pm 0.98)\end{array}$ & $\begin{array}{l}18.9 \\
( \pm 0.923)\end{array}$ & $\begin{array}{l}42.05 \\
( \pm 2.5)\end{array}$ & $\begin{array}{l}105.1 \\
( \pm 1.73)\end{array}$ & $\begin{array}{l}197.2 \\
( \pm 2.68)\end{array}$ & $\begin{array}{l}9.65 \\
( \pm 2.1)\end{array}$ & $\begin{array}{l}18.15 \\
( \pm 1.01)\end{array}$ & $\begin{array}{l}167.35 \\
( \pm 12.72)\end{array}$ & $\begin{array}{l}223.91 \\
( \pm 10.47)\end{array}$ \\
\hline Female & $\begin{array}{l}38.2 \\
( \pm 5.4) \\
t=-0.625 \\
\mathrm{df}=39 \\
p=0.536\end{array}$ & $\begin{array}{l}23.14 \\
( \pm 0.8) \\
t=0.509 \\
\mathrm{df}=39 \\
p=0.614\end{array}$ & $\begin{array}{l}21 \\
( \pm 1) \\
t=-1.537 \\
\mathrm{df}=39 \\
p=0.132\end{array}$ & $\begin{array}{l}38.6 \\
( \pm 1.9) \\
t=1.06 \\
\mathrm{df}=39 \\
p=0.294\end{array}$ & $\begin{array}{l}101.52 \\
( \pm 1.1) \\
t=1.74 \\
\mathrm{df}=39 \\
p=0.09\end{array}$ & $\begin{array}{l}204 \\
( \pm 2.01) \\
t=-2.042 \\
\mathrm{df}=39 \\
\boldsymbol{p}=\mathbf{0 . 0 4 8}\end{array}$ & $\begin{array}{l}5.46 \\
( \pm 1.19) \\
t=1.83 \\
\mathrm{df}=39 \\
p=0.075\end{array}$ & $\begin{array}{l}15.71 \\
( \pm 1.08) \\
t=1.642 \\
\mathrm{df}=39 \\
p=0.109\end{array}$ & $\begin{array}{l}193.28 \\
( \pm 12.34) \\
t=-1.464 \\
\mathrm{df}=39 \\
p=0.151\end{array}$ & $\begin{array}{l}244.62 \\
( \pm 13.03) \\
t=-1.231 \\
\mathrm{df}=39 \\
p=0.226\end{array}$ \\
\hline
\end{tabular}




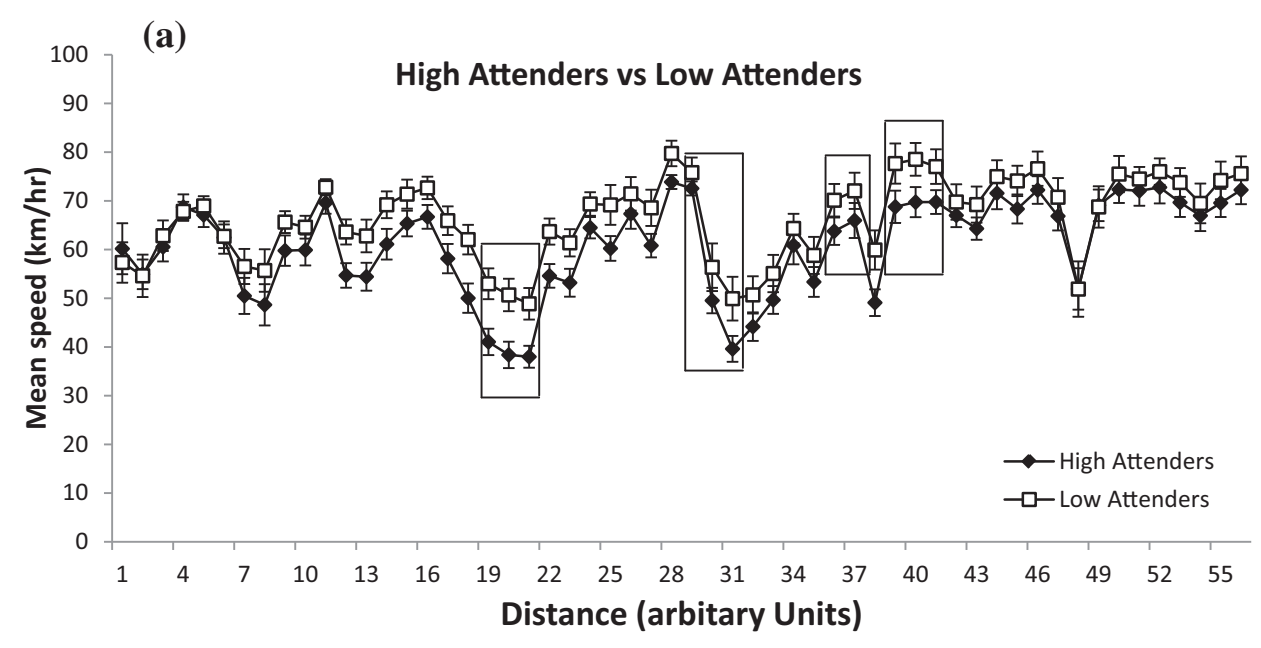

(b)

Bend 1

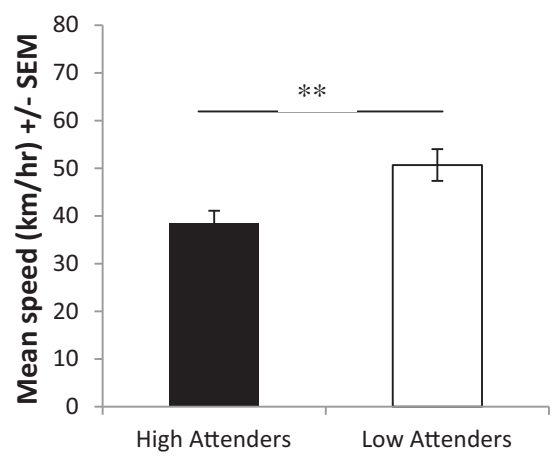

(d)

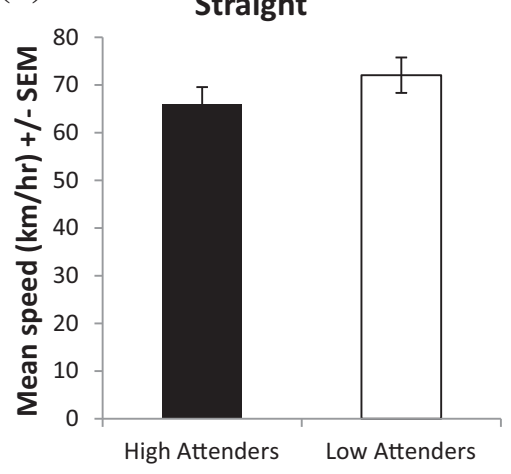

(c)

Bend 2

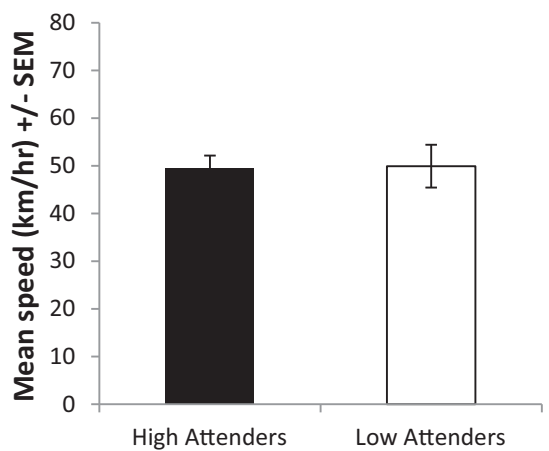

(e)

School

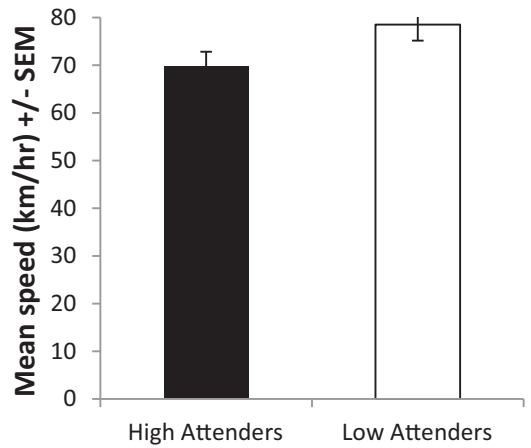

Fig. 2. (a) Comparison of the changes in the average speed $(\mathrm{km} / \mathrm{h})$ between high and low sustained attention drivers across entire route. Bar chart demonstrating differences in average speed ( \pm SEM) between high and low sustained attention groups at (b) bend 1 , (c) bend 2 , (d) the straight stretch of road, and (e) the school. Note that the highlighted boxes in 2a represent the locations of bend 1, bend 2, the straight stretch of road, and the school, respectively.

Regions of interest were identified from the map and route, and these were matched to the appropriate video frames. Speeds at each of these locations were then collated for each person.

\subsection{Statistical analysis}

The data was analysed in Excel and SPSS 17.0 for Windows. Independent $t$-tests and mixed factorial ANOVAs were used to analyse and interpret the data. For figures, significance levels of $p \leqslant 0.05$ were denoted using a single $\left({ }^{*}\right)$ asterisks and levels of $p \leqslant 0.01$ denoted using two $\left.{ }^{(* *}\right)$. In addition, all figures include the standard error of the mean (SEM). 


\section{Results}

\subsection{Driving analysis}

Forty-one participants completed the entire route in an average time of $16.45 \mathrm{~min}(\mathrm{SD}=3.7)$. This compares well to the time of 18 min suggested by Google Maps to travel the road between Dunboyne to Summerhill. The average speed across the route was 63.5 kilometres per hour $(\mathrm{km} / \mathrm{h})(\mathrm{SD}=10.3)$.

\subsection{Sustained Attention}

We initially conducted a median split and divided our participants into two groups based on SART accuracy scores; a high attention $(n=21)$ and a low attention group $(n=20)$. As well as scoring significantly higher on overall accuracy scores $(t(39)=7.437, p=0.001)$ the high attention group was found to show significantly less Errors of Omission and Errors of Commission compared to the low attention group (all $p<0.001$, see Table 1 ). In addition, the high attention groups were also significantly faster in their responses (also see Table 1 ). As our sample consisted mainly of university students and educational levels have been shown to be related to working memory, attention and other cognitive abilities (Meguro et al., 2001), we wanted to ensure the two attention groups were matched in terms of general executive functioning and general intelligence. As such, we then compared the groups on the various control tasks. Table 1 shows no significant difference between the groups on the TMTa $(t(39)=0.593, p=0.556)$, TMTb $(t(39)=0.313, p=0.756)$ and the NART $(t(39)=-0.396$, $p=0.694)$. Table 1 also shows that both groups were matched for both age $(t(39)=1.742, p=0.089)$ and driving experience $(t(39)=1.322, p=0.194)$.

Following this we compared our groups on overall speed on the simulated route and speeds at each of our locations of interest. The average speed for high attention group was $60.8 \mathrm{~km} / \mathrm{h}(\mathrm{SD}=9.6)$, while the average speed for the low attention group was $66.27 \mathrm{~km} / \mathrm{h}(\mathrm{SD}=10.4)$. No significant difference in overall speed was found between the two groups $(t(39)=-1.725, p=0.09)$. The differences in average speed between the high and low attention groups at bend 1 , bend 2 , the straight stretch of road and the school were then compared. There was an overall significant effect for Time $(F(2,78)=3.371, p=0.03$, Eta-squared $=0.08$ ) with both groups slowing down upon approach to the bend (Fig. $2 \mathrm{a})$. There was no Time X Group interaction effect $(F(2,78)=0.138, p=0.872$, Eta-squared $=0.004)$. However there was an overall significant effect for $\operatorname{Group}(F(1,39)=9.593, p=0.004$, Eta-squared $=0.197)$, with the mean speed for the high attention group $(M=38.37, \mathrm{SD}=12.4)$ lower than that for the low attention group $(M=50.67, \mathrm{SD}=14.89$; Fig. $2 \mathrm{~b})$. At bend 2 , there was again an overall significant effect for Time $(F(2,78)=16.20, p=0.001$, Eta-squared $=0.294$ ) with both groups slowing down rapidly upon approach to the bend (Fig. 2a). There was no Time X Group interaction $(F(2,78)=1.028, p=0.363$, Eta-squared $=0.026$ ) or Group effect $(F(1,39)=2.638, p=0.112$, Eta-squared $=0.063)$. Fig. 2c shows the mean speed for the high attention group was 49.53 ( $S D=11.96$ ) and for the low attention group was $49.9(\mathrm{SD}=20.07)$. On the straight stretch of road (Fig. $2 \mathrm{~d}$ ) the mean speed for the high attention group was $65.9(\mathrm{SD}=16.4)$ and for the low attention group it was $72.1(\mathrm{SD}=16.6)$. There was no overall significant effect for Time $(F(1,39)=2.092, p=0.156$, Eta-squared $=0.051)$, Time $\times \mathrm{Group}(F(1,39)=0.009$, $p=0.926$, Eta-squared $=0.001)$ or Group $(F(1,39)=1.863, p=0.180$, Eta-squared $=0.046)$. Finally at the school (Fig. 2e), the mean speed for the high attention group at $69.7 \mathrm{~km} / \mathrm{h}(\mathrm{SD}=14.1)$ and the low attention group at $78.5 \mathrm{~km} / \mathrm{h}$ $(\mathrm{SD}=15.1)$. There was no main effect for Time or Time $\times$ Group interaction effect but the Group effect approached significance $(F(1,39)=3.492, p=0.06$, Eta-squared $=0.082)$.

One possibility that may account for the subtle difference between the high and low attention group is gender. Of the 21 participants in the high attention group 13 were female (62\%), while $60 \%$ of participants in the low attention group were male. Although no gender differences were noted on the majority of the SART measures, a small but significant difference was observed on the SART accuracy scores $(t(39)=-2.042, p=0.048$; see Table 1$)$, with females showing higher accuracy scores than males. Therefore, if gender rather than attention capacity was a factor, we might expect to find gender differences in driving behaviour to occur in places similar to where differences between the two attention groups were found (e.g. bend 1). Fig. 3a shows the changes in the average speed for male and female drivers across the entire route. The average overall speed for males was $67 \mathrm{~km} / \mathrm{h}( \pm 2.32)$, while the average speed for females was $60.22 \mathrm{~km} / \mathrm{h}( \pm 2.01)$. The differences in average speed between male and female drivers at bend 1, bend 2, the straight stretch of road and the school are displayed in Fig. 3b-e. Interestingly, no significant Group effect was found in speed between males $(M=45.98, S D=14.65)$ and females $(M=43.77, \mathrm{SD}=12.21 ; F(1,39)=0.276, p=0.602$, Eta-squared $=0.007)$ at bend 1 or at bend 2 for (males: $M=60.51$, $\mathrm{SD}=16.02$, females: $M=54.08, \mathrm{SD}=10.86 ; F(1,39)=1.697, p=0.20$, Eta-squared $=0.042)$. There was, however, a significant difference in speed between males $(M=72.77, \mathrm{SD}=16.34)$ and females $(M=58.53, \mathrm{SD}=11.07 ; F(1,39)=12.511, p=0.001$, Eta-squared $=0.243$ ) on the straight stretch of road. A significant difference in speed was also observed at the school for males $(M=78.09, \mathrm{SD}=12.59)$ and females $(M=65.99, \mathrm{SD}=11.31 ; F(1,39)=11.466, p=0.002$, Eta-squared $=0.227)$. These results would suggest both gender and attentional capacity have an independent impact on driving behaviour.

\subsection{Reaction to manipulated environment}

We then compared the average speed of all participants for the normal, augmented and redacted manipulations at three different locations along the route. A $3 \times 3$ mixed between-within subjects ANOVA confirmed these findings. No main effect 

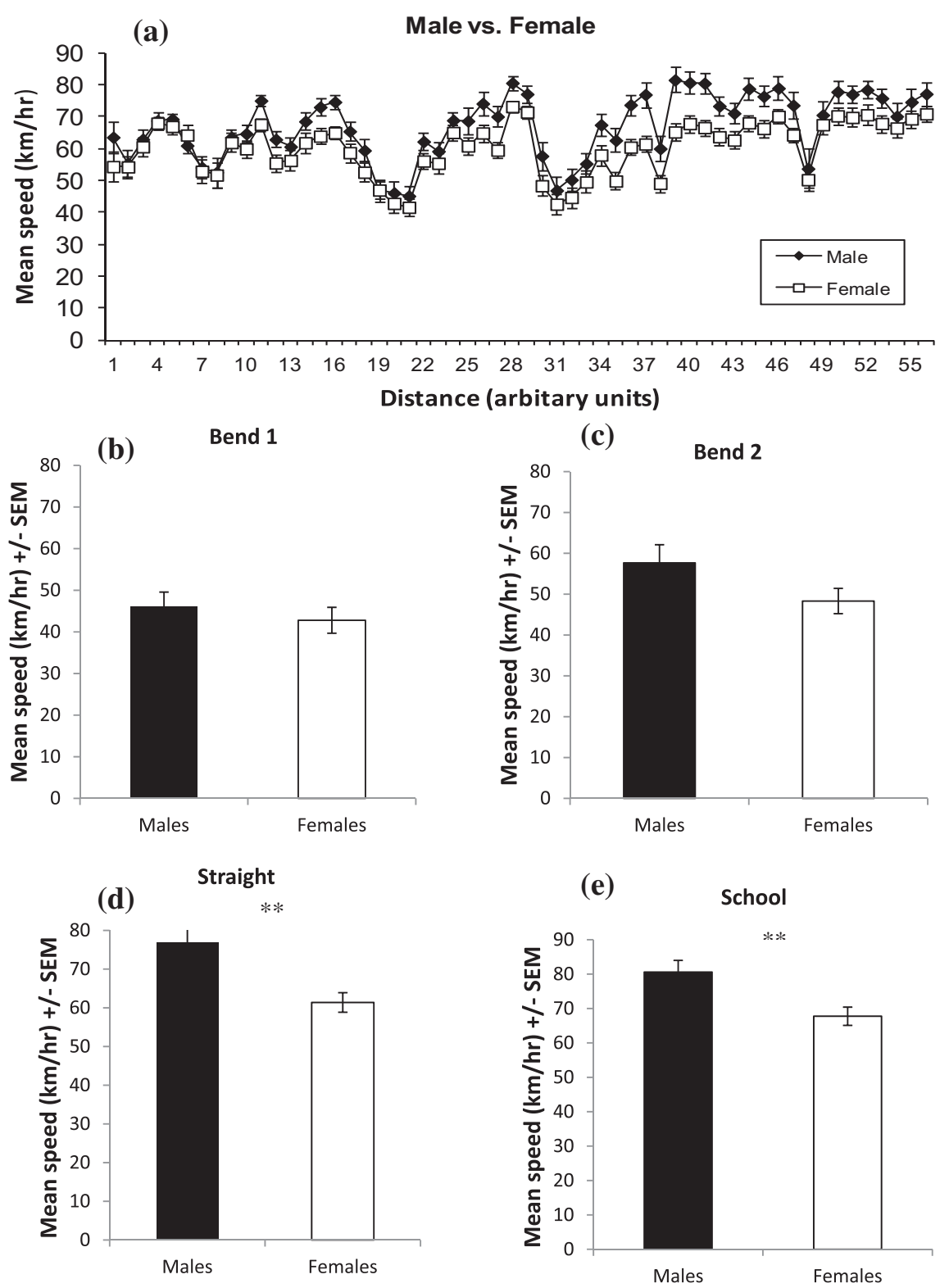

Fig. 3. (a) Comparison of the changes in the average speed $(\mathrm{km} / \mathrm{h})$ between male and female drivers across entire route. Bar chart demonstrating differences in average speed ( \pm SEM) between male and female drivers at (b) bend 1, (c) bend 2, (d) the straight stretch of road, and (e) the school. Note that the highlighted boxes in 3a represent the locations of bend 1, bend 2, the straight stretch of road, and the school, respectively.

for Manipulation $(F(2,38)=3.439, p=0.071)$, Location $(F(2,38)=0.258, p=0.774)$ or Location $\times$ Manipulation interaction effect $(F(2,38)=1.346, p=0.272)$ was found. Having found no differences for location, we then merged the data so we could compare our two attention groups directly on the augmented and redacted scenes. Fig. 4a demonstrates that no overall effect for Manipulation $(F(2,78)=1.422, p=0.247$, Eta-squared $=0.035)$ or Manipulation $\times$ Group interaction $(F(2,78)=0.318$, $p=0.729$, Eta-squared $=0.008$ ) was found. However, we did find a Group effect $(F(1,39)=4.591, p=0.038$, Etasquared $=0.105)$, with the low attention group $(M=67.3 \mathrm{~km} / \mathrm{h}, \mathrm{SD}=9.8)$ having a faster average speed compared to the high attention group $(M=60.52 \mathrm{~km} / \mathrm{h}, \mathrm{SD}=10.08)$. When similar analysis was conducted for males and females (Fig. $4 \mathrm{~b})$, no significant effect for Manipulation $(F(2,78)=1.408, p=0.251$, Eta-squared $=0.035)$ or a Manipulation $\times$ Group interaction effect $(F(2,78)=0.159, p=0.853$, Eta-squared $=0.004)$ was found. Again, an overall significant effect for Group $(F(1,39)=6.726, p=0.013$, Eta-squared $=0.147)$ was reported with males having a faster average speed compared to females. 

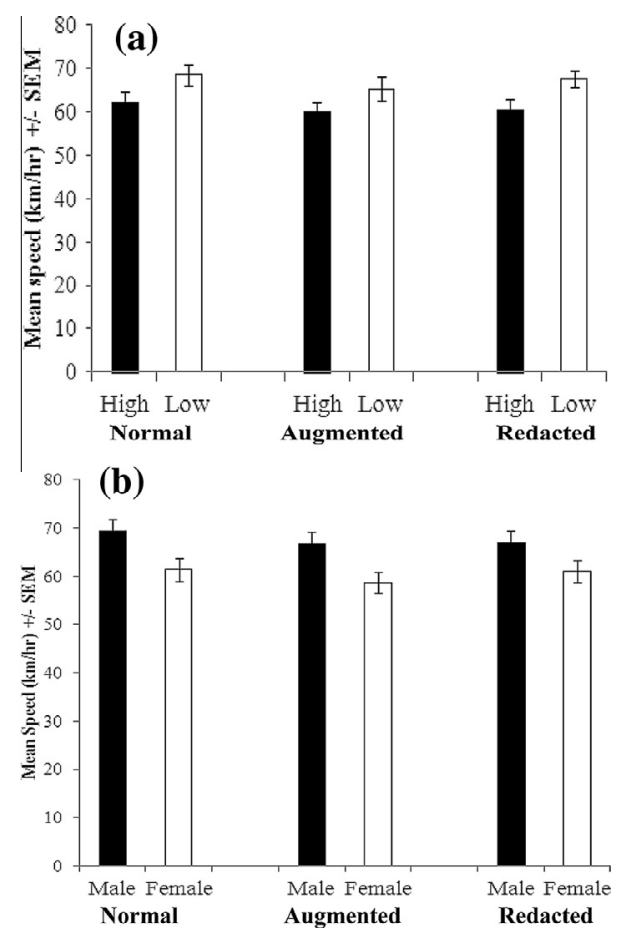

Fig. 4. (a) Bar chart demonstrating the average speed ( \pm SEM) of high and low sustained attention drivers when the road remained as normal, was augmented or redacted. (b) Bar chart demonstrating the average speed ( \pm SEM) of males and females drivers when the road remained as normal, was augmented or redacted.

\section{Discussion}

Using a playback video a number of interesting observations were made. The first is that despite various road/scene manipulations no change in behaviour was found. Neither adding a speed sign (scene augmentation) nor removal of the white line in the middle of the road (scene redaction) had any effect on participants' speed. We had hypothesised that those with high attentional capacity would perhaps have greater 'spare' capacity allowing them to scan and observe their environment more than those with lower attention. This did not seem to be the case. There are a number of potential explanations for this. First, it may be possible that participants did pay attention to the manipulations but made the decision to not change their behaviour, as their behaviour would have limited or no consequences (e.g. due to them being in a simulator and not on the road). Second, the participants did react to the manipulations but as our driving system only measured speed changes, other aspects of their reaction may have been missed. However, we believe that the driving system used is sensitive to speed changes and any reaction by the participant would have been picked up by this measure. Indeed, participants did react strongly to road geometry, slowing down at appropriately at bends etc, thereby demonstrating that the system is sensitive in measuring drivers' reactions. In addition, in a recent study (Brogan, Kaneswaran, Commins, Markham, \& Deegan 2013) we found very good fidelity between our simulator speed data and driver speed data collected using a ground-truth mapping system. A third suggestion is that the participants simply did not pay close enough attention to various elements of the environment, which raises the question of the saliency of the manipulations. However, if the lack of response to speed signs and other changes was found to be translatable to a real driving situation this may raise road safety concerns.

Despite the failures among all participants to observe changes to the environment, when we compared those who had a high score on a measure of sustained attention to those who scored less, we found that participants in the high attention group had a lower speed response at the first bend compared to people in the low attention group. Similarly, participants with high sustained attention scores had a lower speed response through the manipulated locations (Fig. 4a) when compared to those in the low attention group; all manipulated locations were on long straight stretches of road $(\sim 3 \mathrm{~km})$. Thus, although people with high sustained attention generally had a lower speed response through the manipulated locations they failed to react to the manipulations themselves. The observation of a difference between the two groups at the bend is significant as it is at this location, more than any other location along the route, where participants were required to modify their speed. This location may represent an increase in 'task demand' suggested by the TCI model (Fuller, 2000). High attenders, as predicted in the introduction, were perhaps better equipped to deal with this demand compared to those with a lower attentional capacity and therefore reduced their speed to an appropriate level. It is possible that we do not see a similar 
difference between the groups at the second bend because the task demand is now lowered; drivers have dealt with a bend already. While other studies (e.g. Underwood, 2007) would suggest that rural roads do not place a large demand on attentional resources thereby allowing the driver to devote time to inspection of the scenery, we would argue the opposite, that rural roads especially those containing multiple bends, require a consistent high level of sustained attention in a driver. In contrast, while long straight stretches of road (e.g. on a motorway) may generally place an overall lower demand on sustained attention, if the distance along the motorway is increased, the level of sustained attention may become increasing challenged. At this point we would predict that differences would emerge between people with high sustained attentional capacity compared to those with low sustained attention; the lower attention group predicted to demonstrate more variable speeds with increasing journey length.

Driver differences often emerge through both age and driving experience. However, both attentional groups were match in terms of age and number of months driving, as well as other factors. Therefore we suggest that any differences observed were not down to these factors. As mentioned in our introduction though, it is very difficult to measure how learning or developmental factors contribute to attentional capacity. One factor that we cannot rule out completely is gender effects. Over $60 \%$ of the high attention group was composed of females and $60 \%$ of the low attention group was males. Numerous simulator, on-road driving studies (e.g. Laapotti \& Keskinen, 1998; Laapotti \& Keskinen, 2004; Swedler, Bowman, \& Baker, 2012), as well as attitudinal research (Harré et al., 2000), have shown that males generally drive at higher speeds than females. Our findings are consistent with this. But what emerges from our findings are the locations of where the gender differences occur. Interestingly, while there was a significant effect for sustained attention at the first bend, no effect for gender at this location was noted. Furthermore, gender differences in speed were found at both the school and on the straight stretch of road, whereby males drove significantly faster than females in both areas. This was again different to what we observed with the attention groups.

While gender differences were not the main focus of our study, these preliminary findings would suggest that gender and sustained attention are both important factors in driving behaviour. Evidence from several studies (Hartos, Eitel, Haynie, \& Simons-Morton, 2000; Rhodes \& Pivik, 2011) suggests that males tend to engage in more risky driving behaviours more frequently than females. This may be reflected in our data, particularly at the school, where we found that male drivers had a higher speed response compared to females, with a value close to the default speed limit of $80 \mathrm{~km} /$ h. This suggests that males were either not aware of the school's presence or were happy to go faster in this area. In contrast, females appeared to adjust their speed more appropriately at the school. As well as taking more risks, males tend to perceive risk differently to females. For example, females are much more likely to perceive risky driving behaviours as more dangerous than males (Parker, Manstead, Stradling, \& Reason, 1992; Yagil, 1998). Males also appear to believe that they are more skilled in dealing with risky driving situations than females (Farrow \& Brissing, 1990), leading males to have an unrealistic optimism about a situation and a greater illusion of control when compared to females (Laapotti, Keskinen, \& Rajalin, 2003). It is possible that the males in our study did not perceive the risk associated with the presence of the school, or if they did, they felt that they could deal with it, should a situation arise. While gender differences are well documented, our study demonstrates the likelihood of where such differences occur, for example along straight stretches of road and not upon the approach to bends.

There are a number of limitations to our study. First, the participants used were from a random sample of undergraduate university students; using students limits the generalisability of the findings. In addition, due to the relative low sample number used the effect size of the finding was small to moderate. Future studies should endeavour to increase and widen the sample base. A second issue is that driver behaviour is more than just average speed. Other changes that we are unfortunately currently unable to measure (such as lateral position, braking speed, acceleration etc) may also reveal interesting effects. Despite this, speed has been used effectively by many authors to reveal insights into driver behaviour (e.g. LewisEvans et al., 2012), as well as being the primary measure underlying many driving models (e.g. Fuller, 2000, 2005). Third, all simulators (driving or video playback) suffer from the issue of whether the results obtained are directly translatable to on-road situation. However, there is good evidence to suggest that participants took the task seriously; all participants did not simply go at the maximum or constant speed and they reacted well to the changes in road curvature. Further, other authors, examining the role of risk in driver behaviour, have indicated that participants are willing to state that they experience risk, despite the fact they are in a simulator and the risk is zero (Lewis-Evans \& Rothengatter, 2009). However, the use of driving simulators does allow researchers to study relatively realistic driving scenarios in a safe and controlled environment (Aginsky, Harris, Rensinki, \& Beusmans, 1997). By using a video sequence of a real rural Irish road we can establish the precise areas in which particular driving behaviours, such as speeding, tend to occur most frequently. This information may be useful to policy-makers involved in road safety who may be able to design and introduce improved safety measures in these areas. For example, according to the RSA of Ireland $65.9 \%$ of fatal and injury collisions occurred on straight roads, it is also on the straight stretch of road where we showed that both males and people with low levels of sustained attention tended to drive faster. Our findings of inattention to the manipulated visual scenes may need to be explored further in light of road safety issues, especially in relation to speed signs, as well as, upon approaches to schools etc. Future studies also may wish to examine the role of sustained attention while driving along straight roads but over a longer period of time, e.g. on motorways. Further, by combining these approaches with eye-tracking technology we may gain further insights into the role of attention during driving. 


\section{References}

Aginsky, V., Harris, C., Rensinki, R., \& Beusmans, J. (1997). Two strategies for learning a route in a driving simulator. Journal of Environmental Psychology, 17, 317-331.

Al-Balbissi, A. H. (2003). Role of gender in road accidents. Traffic Injury Prevention, 4, 64-73.

Ashendorf, L., Jefferson, A. L., O'Connor, M. K., Chaisson, C., Green, R. C., \& Stern, R. A. (2008). Trail Making Test errors in normal aging, mild cognitive impairment, and dementia. Archives Clinical Neuropsychology, 23, 129-137.

Blakemore, S. J., \& Choudhury, S. (2006). Development of the adolescent brain: Implications for executive function and social cognition. Journal of Child Psychology and Psychiatry, and Allied Disciplines, 47(3-4), 296-312.

Bradski, G., \& Kaehler, A. (2008). Learning OpenCV: Computer vision with the OpenCV library (1st ed.). O’Reilly Media Inc.

Brogan, M., Kaneswaran, D., Commins, S., Markham, C., \& Deegan, C. (2013) Automatic generation and population of graphics-based driving simulator using mobile mapping data for the purpose of behavioral testing of drivers. In Proceedings of 93rd annual meeting of the transportation research board transport research board. Paper Number 14-0473.

Campagne, A., Pebayle, T., \& Muzet, A. (2004). Correlation between driving errors and vigilance level: influence of the driver's age. Physiology and Behavior, $80(4), 515-524$.

Christakou, A., Murphy, C. M., Chantiluke, K., Cubillo, A. I., Smith, A. B., Giampietro, V., et al (2013). Disorder-specific functional abnormalities during sustained attention in youth with Attention Deficit Hyperactivity Disorder (ADHD) and with autism. Molecular Psychiatry, $18(2), 236-244$.

Davies, A. D. M., \& Parasuraman, R. (1982). The psychology of vigilance. London, New York): Academic Press.

Dingus, T.A., Klauer, S.G., Neale, V.L., Petersen, A., Lee, S.E., Sudweeks, J., et al., (2006). The 100-car Naturalistic Driving Study, Phase II-Results of the 100-car field Experiment. Technical Report No. DOT HS 810 593. Washington, DC: National Highway Traffic Safety Administration.

Farrow, J. A., \& Brissing, P. (1990). Risk for DWI: A new look at gender differences in drinking and driving influences, experiences, and attitudes among new adolescent drivers. Health Education E' Behavior, 17, 213-221.

Fuller, R. (2000). The task-capability interface model of the driving process. Recherche Transports Secuirite, 66, 47-59.

Fuller, R. (2005). Towards a general theory of driver behaviour. Accident Analysis Prevention, 37(3), 461-472.

Fuller, R., McHugh, C., \& Pender, S. (2008). Task difficulty and risk in the determination of driver behaviour. Revue Europeene de Psychologie appliqué, 58, $13-21$.

Harré, N., Brandt, T., \& Dawe, M. (2000). The development of risky driving in adolescence. Journal of Safety Research, 31, $185-194$.

Hartos, J. L., Eitel, P., Haynie, D. L., \& Simons-Morton, B. G. (2000). Can I take the car? Relations among parenting practices and adolescent problem-driving practices. Journal of Adolescent Research, 15, 352-367.

Klauer, S. G., Dingus, T. A., Neale, V. L., Sudweeks, J. D., \& Ramsey, D. J. (2006). The Impact of Driver Inattention on Near-crash/crash risk: An Analysis Using the 100-car Naturalistic Driving Study Data. Technical Report No. DOT HS 810 594. Washington, DC: National Highway Traffic Safety Administration.

Kelley-Baker, T., \& Romano, E. (2010). Female involvement in U.S. nonfatal crashes under a three-level hierarchical crash model. Accident Analysis Prevention, 42(6), 2007-2012.

Laapotti, S., \& Keskinen, E. (1998). Differences in fatal loss-of-control accidents between young male and female drivers. Accident Analysis and Prevention, 30 , $435-442$.

Laapotti, S., \& Keskinen, E. (2004). Has the difference in accident patterns between male and female drivers changed between 1984 and 2000 ? Accident Analysis and Prevention, 36, 577-584.

Laapotti, S., Keskinen, E., \& Rajalin, S. (2003). Comparison of young male and female drivers' attitude and self-reported traffic behaviour in Finland in 1978 and 2001. Journal of Safety Research, 34, 579-587.

Lee, S. E., Olsen, E. C. B., \& Simons-Morton (2006). Eyeglance behaviour of novice teen and experienced adult drivers. Transportation Research Record: Journal of the Transportation Research Board, 1980, 57-64.

Lestina, D. C., \& Miller, T. R. (1994). Characteristics of crash-involved younger drivers. In 38th annual proceedings of the association for the advancement of automotive medicine (pp. 425-437). Des Plaines, IL: Association for the Advancement of Automotive Medicine.

Levine, B., Schweizer, T. A., O'Connor, C., Turner, G., Gillingham, S., Stuss, D. T., et al (2011). Rehabilitation of executive functioning in patients with frontal lobe brain damage with goal management training. Frontiers Human Neuroscience, 17, 5-9.

Lewis-Evans, B., de Waard, D., Jolij, J., \& Brookhuis, K. A. (2012). What you may not see might slow you down anyway: masked images and driving. PLoS One, 7(1), e29857.

Lewis-Evans, B., \& Rothengatter, T. (2009). Task difficulty, risk, effort and comfort in a simulated driving task-Implications for Risk Allostasis Theory. Accident Analysis and Prevention, 41(5), 1053-1063.

Manly, T., Robertson, I. H., Galloway, M., \& Hawkins, K. (1999). The absent mind: Further investigations of sustained attention to response. Neuropsychologia, 37(6), 661-670.

McEvoy, S. P., Stevenson, M. R., \& Woodward, M. (2007). The prevalence of, and factors associated with, serious crashes involving a distracting activity. Accident Analysis and Prevention, 39(3), 475-482.

Meguro, K1, Shimada, M., Yamaguchi, S., Ishizaki, J., Ishii, H., Shimada, Y., et al (2001). Cognitive function and frontal lobe atrophy in normal elderly adults: Implications for dementia not as aging-related disorders and the reserve hypothesis. Psychiatry and Clinical Neurosciences, 55(6), 565-572.

Mueller, A. S., \& Trick, L. M. (2012). Driving in fog: The effects of driving experience and visibility on speed compensation and hazard avoidance. Accident Analysis and Prevention, 48, 472-479.

National Roads Authority of Ireland (NRA), (2009) National routes length. http://www.nra.ie/Publications/Transportation/file,17069,en.pdf.

Nelson, H. E., \& McKenna, P. (1975). The use of current reading ability in the assessment of dementia. British Journal of Social and Clinical Psychology, 14, $259-267$.

Nuechterlein, K. H., Parasuraman, R., \& Jiang, Q. (1983). Visual sustained attention: Image degradation produces rapid sensitivity decrement over time. Science, 220(4594), 327-329.

O'Halloran, A. M., Finucane, C., Savva, G. M., Robertson, I. H., \& Kenny, R. A. (2014). Sustained attention and frailty in the older adult population. Journal of Gerontology B Psychology Sciences, 69(2), 147-156.

Parker, D., Manstead, A. S. R., Stradling, S. G., \& Reason, J. T. (1992). Determinants of intention to commit driving violations. Accident Analysis and Prevention, 24, 117-131.

Posner, M. I., \& Petersen, S. E. (1990). The attention system of the human brain. Annual Review of Neuroscience, 13, 25-42.

Pradhan, A. K., Divekar, G., Masserang, K., Romoser, M., Zafian, T., Blomberg, R. D., et al (2011). The effects of focused attention training on the duration of novice drivers' glances inside the vehicle. Ergonomics, 54(10), 917-931.

Pradhan, A. K., Hammel, K. R., DeRamus, R., Pollatsek, A., Noyce, D. A., \& Fisher, D. L. (2005). Using eye movements to evaluate effects of driver age on risk perception in a driving simulator. Human Factors, 47, 840-852.

Reiten, R. M. (1958). Validity of the Trail Making Test as an indicator of organic brain damage. Perceptual and Motor Skills, 8, $271-276$.

Rhodes, N., \& Pivik, K. (2011). Age and gender differences in risky driving: The roles of positive affect and risk perception. Accident Analysis E Prevention, 43, 923-931.

Road Safety Authority of Ireland (RSA), 2011. Road Collision Factbook <http://www.rsa.ie/Documents/Road\%20Safety/Crash\%20Stats/ 2011_Road_Collision_Fact_Book.pdf>.

Robertson I. H. (in press). A right hemisphere role in cognitive reserve. Neurobiology Aging. pii:S0197-4580(13)00612-X. http://dx.doi.org/10.1016/ j.neurobiolaging.2013.11.028. 
Robertson, I. H., Manly, T., Andrade, J., Baddeley, B. T., \& Yiend, J. (1997). 'Oops!': Performance correlates of everyday attentional failures in traumatic brain injured and normal subjects. Neuropsychologia, 35, 747-758.

Rosvold, H. E., Mirsky, A. F., Sarason, I., Bransome, J. D., \& Beck, L. H. (1956). A continuous performance test of brain damage. Journal of Consulting Psychology, 209(5), 343-350.

Rubio, S., Diaz, E., Martin, J., \& Puente, J. M. (2004). Evaluation of subjective mental workload: a comparison of SWAT, NASA-TLX and workload profile methods. Applied Psychology International Review, 53, 61-86.

Sagberg, F. (2001). Accident risk of car drivers during mobile telephone use. International Journal of Vehicle Design, 26, 57-69.

Sánchez-Cubillo, I., Periáñez, J. A., Adrover-Roig, D., Rodríguez-Sánchez, J. M., Ríos-Lago, M., Tirapu, J., et al (2009). Construct validity of the Trail Making Test: Role of task-switching, working memory, inhibition/interference control, and visuomotor abilities. Journal of International Neuropsychology Society, $15,438-450$.

Staub, B., Doignon-Camus, N., Després, O., \& Bonnefond, A. (2013). Sustained attention in the elderly: what do we know and what does it tell us about cognitive aging? Ageing Research Reviews, 12(2), 459-468.

Swedler, D. I., Bowman \& Baker, S. P. (2012). Gender and age differences among teen drivers in fatal crashes. Annals of Advances in Automotive Medicine, 56 , 97-106.

Underwood, G. (2007). Visual attention and the transition from novice to advanced driver. Ergonomics, 50, 1235-1249.

Yagil, D. (1998). Gender and age-related differences in attitudes toward traffic laws and traffic violations. Transportation Research Part F: Traffic Psychology and Behaviour, 1, 123-135. 